the Lepidoptora may have been tentative, and well within the competence of ordinary variability.

The above sufficiently trite train of thought has been suggested to me by the consideratio of analogous facts known to every angler. Many fishes greedily snap at anything that glistens or is hishly coloured, especially if it be rapidly drawn through the water, and the slight additional disguise imparted to artificial bait of this description by a spinning motion renders it very attractive. The highly specialised salmon is easily deceived, and the most killing artificial flies for this fish make no pretence to resemble anything in niture, and a e attractive in proportion to their gaudiness. The same is true of his congener the trout, although this fish appears to be somewhat more æstheric in his tastes; and the mo.t useful artificial flies employed to entice him are mere generalised imitations of his natural food. Indeed, on these grounds no less than on those of anatomy, it cannot be doubted that the Tileostei-albeit highly specialised of their kind -have failed to develop that acuteness of vision which their rapid movements would seem to render de-irable, and are yet in the stage in which a very imperfect mimicry misleads them; and it is not an unreasonable presumption that birds were once in a very similar condition, from which they have emerged in consequence of the necessity for frequent and abundan: supplies of food entailed upon them by their active $m$ ode of life. Under these circum itances it must have gone hard with the belpless caterpillar, so toothsome and nutritious, seeing that he could not, like the mature Phryganida and Ephemeride, keep out of harm's way by shunning the element inhabited by his natural foe; and hence arose the necessity for his protective modification. How urgent was the need for this is amply shown by the fact that several distinct modes of protection have been enlisted in his defence, viz. cuticular hypertrophy resulting in hairiness, mimicry of the vegetation on which he feeds and lives, and un palatable flavour; to which has been superadded mimicry of the unpalatable forms by those of good flavour. But even with all this adventitious aid the struggle would probably have proved exterminating to him by reason of the voracity of birds, had not the teeming imago participated in the protective modifications, and thereby been enabled to maintain the balance of supply and demand necessary for the survival of the order.

Wycombe Court, Bucks

Paul Henry Stokoe

\section{Threatened Extinction of the Elephant}

THE threatened extinction of any existing species of plant or auimal cannot fail to be matter of real concern to all students of science, who ought to neglect no feasible means for preventing so deplorable an occurrence.

Of the few gigantic mammals still living on the surface of ou planet, none possesses more interest and none are more worthy preservation than the elephant. Yet it is an accepted conclusion that the elephant is doomed to extinction, and that within a measurable period of time this majestic quadruped will have suffered the fate of the Dodo. Cannot such a calamity be prevented? Surely the destruction of elephants might be legally controlled (in India, at any rate), and their capture (for domestication) might be limited, as it is well known they never breed in confinement. The continuous rise in the market-price of ivory, and its recent unprecedented scarcity as an article of commerce, are ominous signs, and renders it incumbent on the votaries of science to consider what may be done in the matter. It is no question of mere sentiment-it is of vital importance; and if "ancient monument:, ruins, \&c.," are worth protecting, it cannot be denied that so remarkable and interesting a creature as our colossal Pachyderm merits some effort in his behalf.

EDWARd E. PriNCe

United College, University of St. Andrews, March I5

\section{A Curious Case of Ignition}

ONE fine morning recently, as two ladies were standing to gether in the drawing-room of a house in this neighbourhood, smoke was observed to rise from the dress of one of them. This was found to be due to ignition by the solar rays focused on her dress by the lens of a graphoscope which stood on the table. Similar cases of accidental concentration of the sun's rayz have, I am aware, been recorded. It would be interesting to know whether any serious fires have thus originated. One can easily imagine circumstances which would favour such results from a simple cause.

Finchley, March 26

\section{SINGING, SPEAKING, AND STAMMERING}

\section{I.--SINGING}

THE voice, essentially a musical instru nent, has only of late been scientifically considered. Even now singing is too much dealt with as an art, and its acquirement as an accomplishment. The professional mystery with which it is surrounded serves no good purpose, and favours empiricism. At ladies' schools the old fiction of what are quaintly termed "finishing lessons" still survives ; they often succeed in finishing any prospect; the pupil may have had of becoming a singer. Most of the current primers and tutors are.ludicrously vague and feeble, many methods are absolutely injurious to the voice; for the improvement of which one ingenious inventor has suggested the use of a false palate, and another the fitting of singers' mouths with a sort of bell-shaped snout or proboscis to act as a resonator. A chorus of such proboscidians on the Handel orchestra would be an appalling sight. The real foundation of our knowledge rests on the researches of Helmboltz on the physical, and of Garcia on the physiological, side. The classical discoveries of the former as to the production of vowel-sounds by the superaddition of a varying harmonic in the mouth-cavity, and of the latter by the examination of the larynx in action by means of a mirror, brought before the Royal Society in May, 1855, have formed the substratum of much which has now become the common property of scientific men. Dr. Bristowe, in his Lumleian lectures of 1879 , has added some pathological data of considerable value, and Dr. Walshe, in his "Dramatic Singing, Physiologically Estimated," has touched on points connected with the sympathetic and emotional power which this most perfect of instruments can be made to exercise. It owes this in a great measure to the fart that it can combine musical sounds with significant words, and thus interest at once the ear and the intelligence. Af er a demonstration of the action of the larynx and fauces in phonation, illustrated by some excellent photographs taken from his own larynx by Mr. Emil Behnke, and thrown on the screen, vowel. sounds were shown to be thirteen in number in the English language, with six more in French and German, fifteen of these being oral in origin, and four, all French sounds, nasal. Consonants were about sixteen in number, and had been called "noises" by Max Müller, owing to their comparatively unmusical character. They are chiefly caused by some check or obstruction to the laryngeal note. A diagram of Madame Seiler's was, however, shown which indicates that there is an oral resonance-note even for consonants, though it is much more obscure and uncertain than that of the vowels. Meiville Bell's division of vocal sounds into vowels, consonants, and glides or semivowels was adverted to, and his ingenious device of visible speech briefly explained, but left for fuller consideration in the second lecture. The contrast was then pointed out between singing, in which the musical notes predominate and are separate or discrete; intoning, which is speech intentionally rendered monotonous for better transmission in large spaces like cathedrals; recitative, which is the converse of the former, being singing partially loosened from the trammels of time, rhythm and melody, so as to approximate to speaking; speech itself, which uses continuous inflection; declaiming, which is speech with the addition of a histrionic and emotional element; reading, which is a faint and as it were distant reproduction of speaking in a lower key, quieter and less marked in accent than in speaking viva voce; and whispering, which is purely oral, without a laryngeal ground note, and which may be termed voiceless speech.

The different qualities, compass, and register of voices ' Abstract by the Author of three Lectures at the Royal Institution, by
W. H. Stone, M.D.F.R.C.P. 